Research Article

\title{
Field Robot and Sensing System
}

\author{
Eiji Hayashi* \\ Department of Mechanical Information Science and Technology, Kyushu Institute of Technology, 680-4, Kawazu, Iizuka, Fukuoka 820-8502, Japan
}

\section{ARTICLE INFO}

\section{Article History}

Received 17 November 2018

Accepted 20 December 2018

Keywords

Field sensing forestry

agriculture

industry

\begin{abstract}
Labors in which forestry and agriculture and factory, are working in severe circumstance. So, such workers are necessarily declines and decreases. However, it is important for us to keep going in economy, life and nature. Therefore, to prevent a devastation of the forest, the safety and the lack of food and work in harsh environments, we are thinking alternative technologies that a part of severe and dangerous works are taken robot instead of such workers. Some changes are needed that they are seen innovation such as the generation of a new industry by new technologies using AI and intelligent to improve how to recognize and express more and more of the things that we have various desires.
\end{abstract}

(C) 2019 The Authors. Published by Atlantis Press SARL.

This is an open access article distributed under the CC BY-NC 4.0 license (http://creativecommons.org/licenses/by-nc/4.0/).

\section{INTRODUCTION}

Japan's population is decreasing after a peak in 2008 due to aging of the population and declining birthrates. Such shrinking population will be having a major impact to build a sustainable economy and society over a long-term period, but almost all people feel that the effects for a short term are small and negligible. Japan's economy and society will require more development in technologies such as artificial intelligence and robots to make up for a decline in the labor force. However, the decline of the labor force already invites the labor shortages in the industries. Therefore, the Japanese government aims to introduce a new residence status that the foreign workers are accepted in the 14 business sectors which are restaurants, hotels, nursing care, building cleaning, agriculture, fishery, food and beverage, materials processing, industrial machinery, electronics and electric machinery, construction, shipbuilding, vehicle maintenance, and airport ground handling and aircraft maintenance.

The technology of robotics has provided efficient productivity, quality and safety in factory as well as improved operability so far. The developing robots in forestry, agriculture and food factory are active nowadays since AI and robotics technologies has progressed rapidly. Robot in the future has to have the work capacity or the co-operation cooperativeness equivalent to the skilled worker. It is too difficult to make up for the labor shortages only in such robotics technologies at the present.

This paper reports on field robot and sensing system [1-4] as applications of the robotics and AI to the agriculture, the forestry, the food factory and future industrial factory.

Email:haya@mse.kyutech.ac.jp

\section{AGRICULTURE}

A decline of Japan's agriculture has two big problems related to work in the severe environmental conditions such as hot summer climate and labor shortage. Foreign agriculture uses a large-scale management represented by United States, Australia and The Netherlands using the agricultural machines or the environmental control technology introduced the latest technologies.

\subsection{Present State of Japan}

About 4.42 million ha of the Japanese are of the cultivated land in 2018 is estimated to be $54.4 \%$ of paddy fields, $45.6 \%$ exclusive use for meadows and $6.3 \%$ land under permanent crops of the total amount of the fields.

Survey results are described in the meeting's materials of Cabinet Secretariat of Government of Japan as is shown in Figure 1.

The farmers who mainly engaged in farming is estimated to be 1.50 million persons, average age: 66.7 in 2017, compared with 2.05 million persons, average age: 66.7 in 2010. Taking Japan's rapidly decreasing working population to consideration, it will be too severe in reality for the future agriculture to substantially decrease the farmers. The age structure of farmer in each country shown in Figure 2 reveals that the Japanese farmers of this kind are more likely to be "mainly and significantly aged farmers" than other countries.

\subsection{Agricultural Technology}

Nowadays, it is important to improve the labor productivity and the local adaptability so that the agriculture product can be produced 


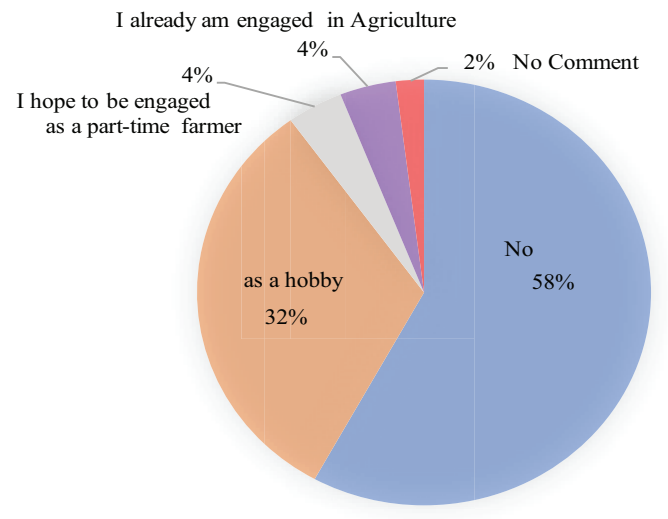

Figure 1 Question: Do you hope to be engaged in the agriculture?

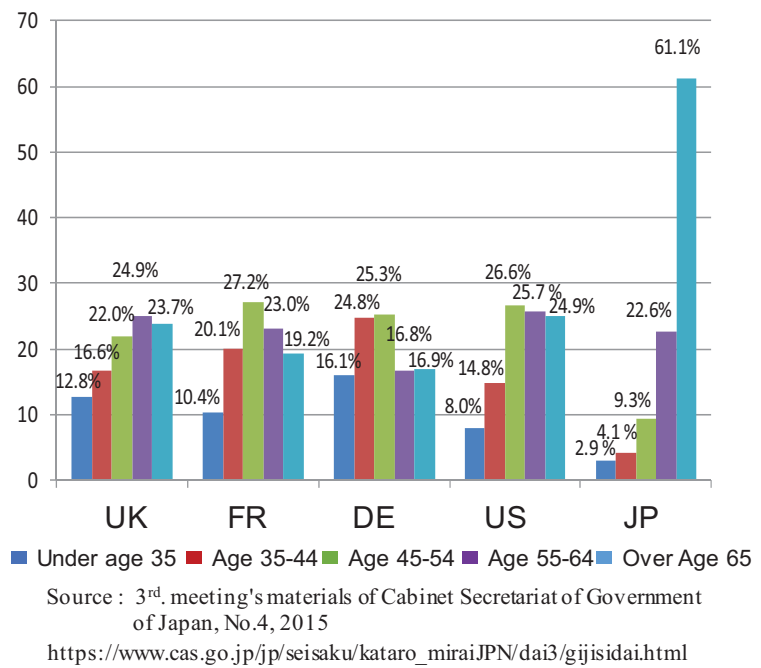

Figure 2 The age structure of farmer in each country. The Japanese farmers are more likely to be "mainly and significantly aged farmers".

in quantity. The technology in the agriculture has promoted the introductions of management and automation system [5,6], environmental control for the green house like a plant factory, especially in The Netherlands. The plant factory cultivates plant in the facility utilizing artificial control of light, temperature, moisture, and carbon dioxide concentrations all year around. The producing crops almost are vegetables which are divided into fruit vegetable such as tomato, strawberry, cucumber or eggplant, and green vegetable such as lettuce, spinach, green onion and herbs.

Such a plant factory has the issues as follows:

- Almost all work is done from raising seedling to harvesting by hand.

- Initial cost and running cost.

\subsection{Automation}

All work from seedling to harvesting is difficult to automatically do by robotic technology because of the influence of light in the various situation [7-9]. It is important for robot to reduce and suppress the influence of light including infrared. The influence of light occurs due to regular reflection light bounces off from the smooth surface. If the intensity of the regular reflection increases, a color of object is recognized as different color. Human usually sees a color of the smooth surface from an angle occurring no regular reflection to reduce and suppress.

This phenomenon has various influences on the recognition for degree of mutilation of crop, controlling pests and inspect, crop disease diagnosing, robot's posture and travelling for the harvesting [10] as shown in Figure 3.

\subsection{Malaysia}

In mainly Malaysia and Indonesia, the palm oil industry has developed more active with the palm plantation because oil palm is a kind of tropical plants is grown on a large scale as the commercial crops.

The infield FFB in the plantation of Sime Darby in Figure 4 has 2724 ha in Sepang Estate. This area's acclivity occupies $42.5 \%$ (1158 ha) of 0-6 degree from flat to undulating, $19.4 \%$ of 6-12 degree.

In case of SD2 (1699 ha) in Sepang Estate, the mature oil palm area is broken into nine blocks to maintain the harvesting rounds within approximately 10 days.

The robot [11] has to be aimed autonomously $2-2.5 \mathrm{~h} /$ task (including traveling time), depending on a terrain and weather. If such robot can achieve, dozens of work rate and people would be reduced and provided more efficient to the plantation.

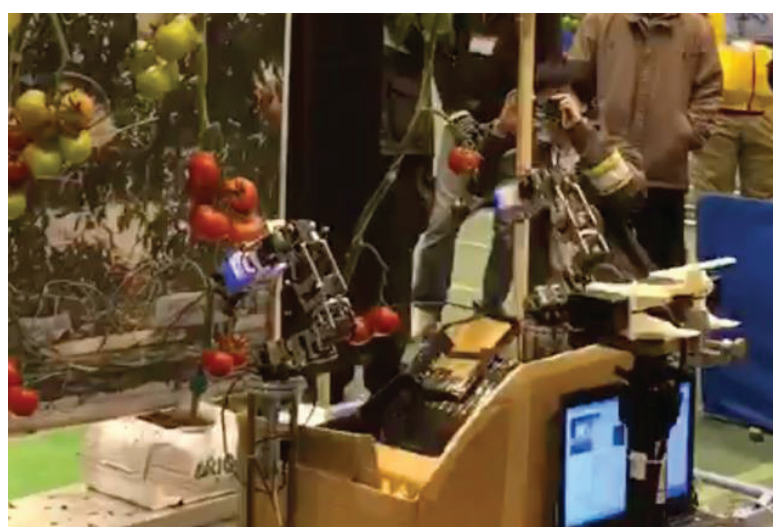

Figure 3 The tomato harvesting robot picks a tomato. This robot can pick one of the tomatoes around $20 \mathrm{~s}$.
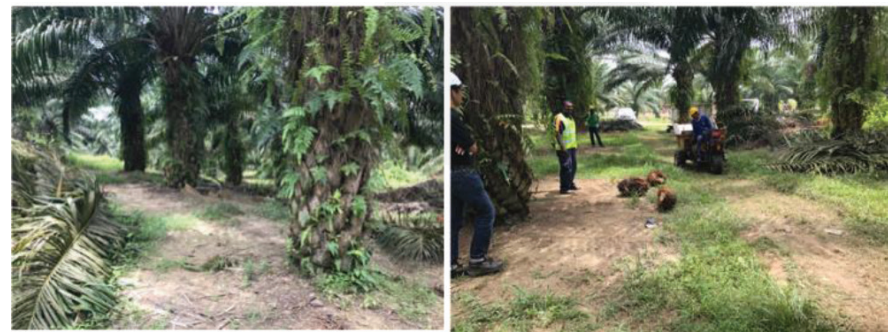

Figure 4 The plantation and dropped fruit bunches in Sime Darby's plantation. 


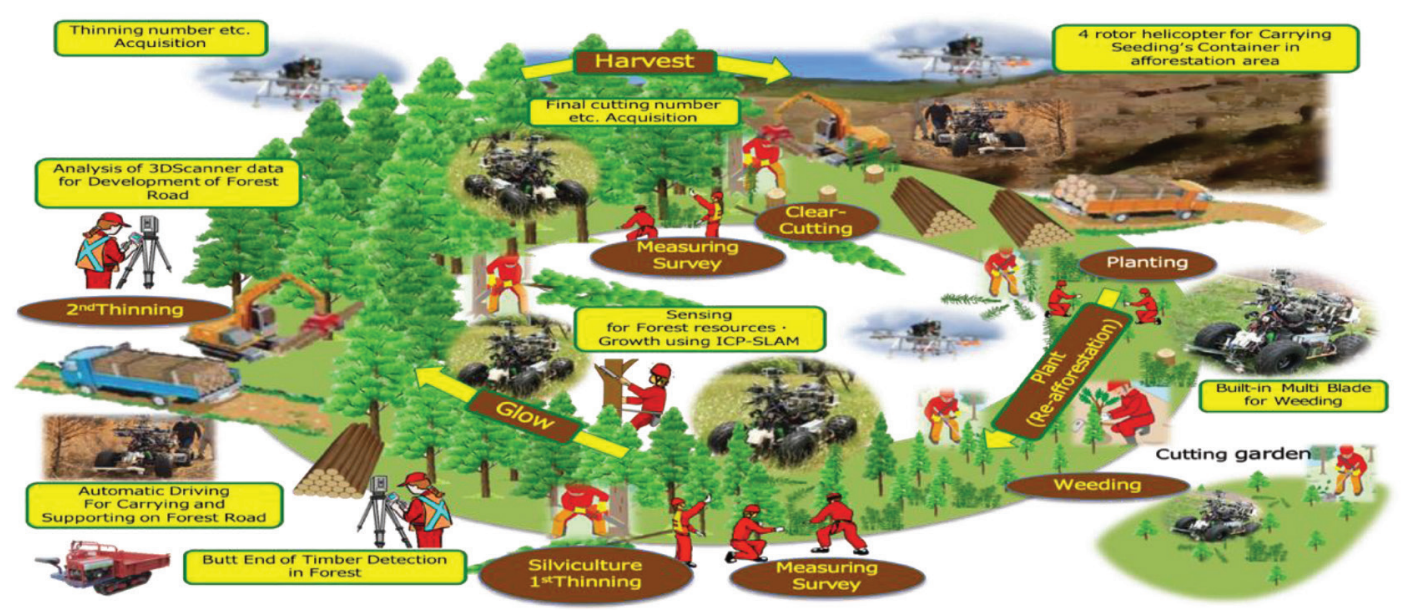

Figure 5 The cyclical use of the forests as circulative resources.

\section{FORESTRY}

Japan has one of the world's largest forests, and the amount of the forests area accounts approximately 25 million ha and 66\% of Japan's land area of 37.8 million ha. However, the labor force population of Japan declines with the aging over the long term, and is about 45,000 people in 2015 .

The forests in Japan are almost the plantation forests made by planting the seedings which cover the area of 10 million ha of the forests in Japan, and are consisted of Japanese cedar, Japanese cypress which are a type of leaved tree.

Although the forestry cycle is plant, glow and harvest, nowadays the Japanese government has promoted the cyclical use of the forests as circulative resources in Figure 5 in facing the all-out harvest of the plantation forests that will cause the vicious cycle in large scale logging as well as deterioration of the forest.

\subsection{Forestry Technology}

The forestry is needed as follows:

- Forest information system to measure the timber.

- Volume and the height of trees and to analyze the tree community in the forest.

- Carrying system of the pot for the seedings using the drone etc.

- Weeding robot [7] system for a steep mountain slope.

Since the Japanese mountain has the steep slope, the workers are too taught to operate the planting and the weeding under the blazing the sun as well as the forcing various painful work postures.

\section{CONCLUSION}

Recently, although there are various issues in global, robotics has potential for development and improvement to solve them using networks and AI. This paper described that there are only a few example of the agricultural and the forestry robots and systems as the field robotics and sensing system. As the related issues, the robotic technologies are needed the robotic arm for factory automation or food factory with less teaching and the autonomous motion using AI processing, the autonomous moving type robot for iron ores and cokes in ironworks, cleaning robot for the drifted garbage on the seashore and so on.

\section{CONFLICTS OF INTEREST}

The authors declare they have no conflicts of interest.

\section{REFERENCES}

[1] W. Jitviriya, M. Koike, E. Hayashi, Emotional model for robotic system using a self-organizing map combined with Markovian model, J. Rob. Mechatron. 27 (2015), 563-570.

[2] S. Chumkamon, E. Hayashi, K. Masato, Intelligent emotion and behavior based on topological consciousness and adaptive resonance theory in a companion robot, Biol. Inspired Cogn. Archit. 18 (2016), 51-67.

[3] A. Mowshowitz, A. Tominaga, E. Hayashi, Robot navigation in forest management, J. Robot. Mechatron. 30 (2018), 223-230.

[4] A. Tominaga, E. Hayashi, A. Mowshowitz, Development of navigation system in field robot for forest management, 2018 Joint 10th International Conference on Soft Computing and Intelligent Systems (SCIS) and 19th International Symposium on Advanced Intelligent Systems (ISIS), IEEE, Toyama, Japan, 2018, pp. 1142-1147.

[5] K. Imou, Automatization and robotization of agricultural machinery, J. Robot. Soc. Japan 35 (2017), 376-378.

[6] H. Sori, H. Inoue, H. Hatta, Y. Ando, Effect for a paddy weeding robot in wet rice culture, J. Robot. Mechatron. 30 (2018), 198-205.

[7] W. Nakagawa, Current status and issues of robotization of agricultural machinery and future prospects, J. Robot. Soc. Japan 35 (2017), 387-389.

[8] R. Fukui, K. Kawae, S. Warisawa, Development of a tomato volume estimating robot that autonomously searches an appropriate measurement position - basic feasibility study using a tomato bed mock-up, J. Robot. Mechatron. 30 (2018), $173-179$ 
[9] A. Shinjo, M. Kudo, The practical use of IT in agriculture: the movement into high-value-added crops and integrated solutions, J. Inst. Electron. Inform. Commun. Eng. 96 (2013), 280-285 (in Japanese).

[10] S. Keita, E. Hayashi, W. Jitviriya, Development of Behavioral Robot Using Imitated Multiplex Neurotransmitter System, The
Proceedings of The 2017 International Conference on Artificial Life and Robotics, 22 (2017), 338-341.

[11] T. Fujinaga, S. Yasukawa, B. Li, K. Ishii, Image mosaicing using multi-modal images for generation of tomato growth state map, J. Robot. Mechatron. 30 (2018), 187-197.

\section{Author Introduction}

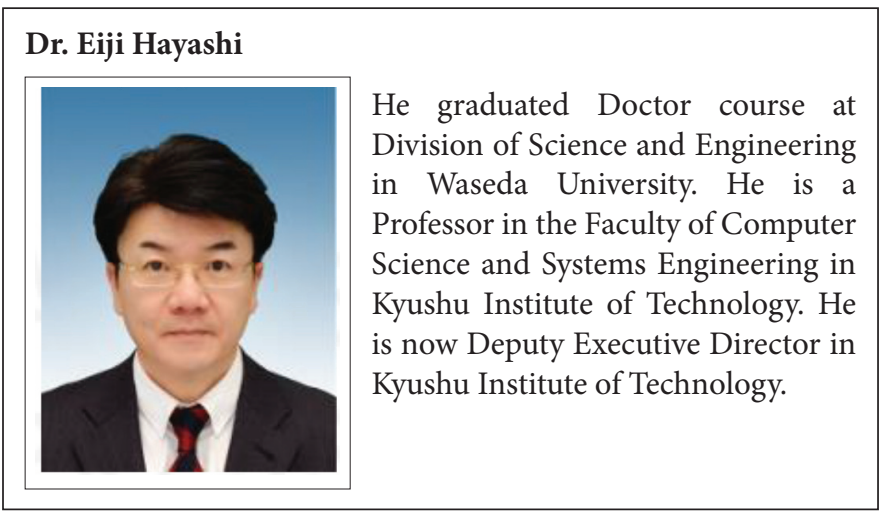

